\title{
Sistem Informasi Karya Inovatif berbasis CMS Wordpress Studi Kasus STIKI Malang
}

\author{
Adnan Zulkarnain', Arif Tirtana², Decya Windri Sukmawati Susanto ${ }^{3}$ \\ STIKI MALANG \\ 19adnan.zulkarnain@ stiki.ac.id, ${ }^{2}$ arif.tirtana@ stiki.ac.id, ${ }^{3} 181221001 @$ stiki.ac.id
}

\begin{abstract}
ABSTRAK. Perkembangan teknologi berpengaruh terhadap dunia pendidikan terutama teknologi berperan sebagai media penyebaran informasi melalui internet. Dengan adanya teknologi maka informasi dapat diakses dengan sangat cepat dan mudah. Sistem informasi berbasis web merupakan salah satu produk dari perkembangan teknologi yang ada. Melalui sistem informasi pengelolaan data tidak memiliki batasan tempat dan waktu. Pengembangan sistem informasi karya inovatif di STIKI Malang dibutuhkan untuk memudahkan pengelolaan data karya yang sudah dibuat oleh mahasiswa maupun dosen. Metode yang digunakan untuk mengembangkan sistem informasi karya inovatif ini adalah metode waterfall, karena metode ini memiliki struktur yang berurutan sehingga proses pengembangan menjadi lebih terkontrol. Pengembangan sistem informasi karya inovatif STIKI Malang menggunakan aplikasi open source yaitu CMS (Content Management System) Wordpress guna mempercepat proses pengembangan sistem informasi. Sistem informasi yang dikembangkan memanfaatkan beberapa plugins wordpress seperti Advanced Custom Fields dan Pods - Custom Content Types and Fields. Sistem informasi karya mahasiswa yang sudah dibuat dilakukan proses pengujian menggunakan metode black box testing untuk memastikan semua fungsi sistem informasi berjalan dengan baik.
\end{abstract}

Kata Kunci: Sistem Informasi; Content Management System; Wordpress;Open Source;

\begin{abstract}
Technological developments affect the world of education, especially technology plays a role as a medium for disseminating information through the internet. With the technology, information can be accessed very quickly and easily. Web-based information system is one product of the development of existing technology. Through the data management information system, there are no restrictions on place and time. The development of an Sistem Informasi Karya Inovatif at STIKI Malang is needed to facilitate the management of work data created by students and lecturers. The method used to develop an Sistem Informasi Karya Inovatif is the waterfall method, because this method has a sequential structure so that the development process becomes more controlled. The development of an Sistem Informasi Karya Inovatif STIKI Malang uses an open source application, CMS (Content Management System) Wordpress to accelerate the process of developing information systems. The information system developed utilizes several WordPress plugins such as Advanced Custom Fields and Pods - Custom Content Types and Fields. The information system of student work that has been made is carried out by the testing process using the black box testing method to ensure all information system functions are running well.
\end{abstract}

Keywords: Information System; Content Management System; Wordpress;Open Source;

\section{PENDAHULUAN}

Teknologi mengalami perkembangan yang sangat pesat dari tahun ke tahun. Terutama dalam dunia pendidikan, teknologi memiliki peranan yang sangat penting terutama sebagai media penyebaran informasi. Dengan adanya teknologi, informasi saat ini dapat diakses dengan sangat cepat serta bisa didapatkan dimanapun asalkan terhubung dengan jaringan internet. (Handayani, Febriyanto, \& Kristanti, 2019). Salah satu perkembangan teknologi yang sangat terasa perkembangannya adalah internet. Internet saat ini bisa dibilang menjadi tumpuan utama media penyebaran informasi yang cepat dan mudah (Ardiastuti, Widarno, \& Harimurti, 2020).

Website merupakan salah satu bagian dari teknologi internet yang memiliki fungsi sebagai media penyebaran informasi (Purba, Karim, \& Trianovie, 2020; Rochman, Hanafri, \& Wandira, 2020). Dengan berkembangnya teknologi pembuatan website maka sistem informasi dapat dibuat berbasis website sehingga nantinya dapat diakses oleh siapapun yang membutuhkan informasi tidak terbatas oleh tempat dan waktu. Sistem informasi merupakan salah satu bagian dari teknologi informasi yang dibuat dengan tujuan adalah untuk menyelesaikan masalah terutama terkait dengan mengelolaan data (Hidayat \& Muttaqin, 2020; Karim \& Purba, 2019). 
Dengan adanya sistem informasi berbasis web proses penyebaran serta mengelolaan informasi terbukti menjadi lebih efektif dan efisien karena informasi dapat diakses dengan cepat dan mudah (Purwati, Suryani, \& Hamzah, 2020). Pengembangan sistem informasi berbasis web dapat dilakukan dengan cara membangun dari awal menggunakan bahasa pemrograman tertentu. Akan tetapi, pengembangan sistem berbasis web membutuhkan waktu yang tidak sedikit terutama membuat kode program. Kondisi saat ini pengelolaan karya-karya yang dihasilkan baik oleh mahasiswa maupun dosen, masih dilakukan secara manual. Sehingga masih menyulitkan mahasiswa maupun dosen mengakses informasi terkait karya-karya inovatif yang sudah dihasilkan selama ini.

Dari penjelasan yang sudah disampaikan sebelumnya, maka dibuatlah sistem informasi karya inovatif berbasis CMS Wordpress guna mempercepat proses pengembangan serta memudahkan pengelolaan data karya inovatif di STIKI Malang.

\section{METODE PENELITIAN}

Kondisi yang terjadi saat ini proses pencatatan data karya inovatif dilakukan secara manual menggunakan aplikasi pengolah data yaitu Microsoft Excel dan Google Sheets. Serta proses penyebaran informasi hanya melalui email. Sehingga proses publikasi informasi menjadi terbatas. Maka dibuatkan sistem informasi karya inovatif dengan menggunakan metode waterfall. Metode waterfall dipilih karena metode ini memiliki pendekatan yang sistematis (Rachmatsyah, Nafisha, \& Prasetyo, 2019), serta sering digunakan dalam proses pengembangan sistem informasi. Tahapan pada metode waterfall adalah tahap requirement, design, implementation, testing dan maintenance yang dikerjakan secara berutan seperti ditunjukkan pada gambar 1 .

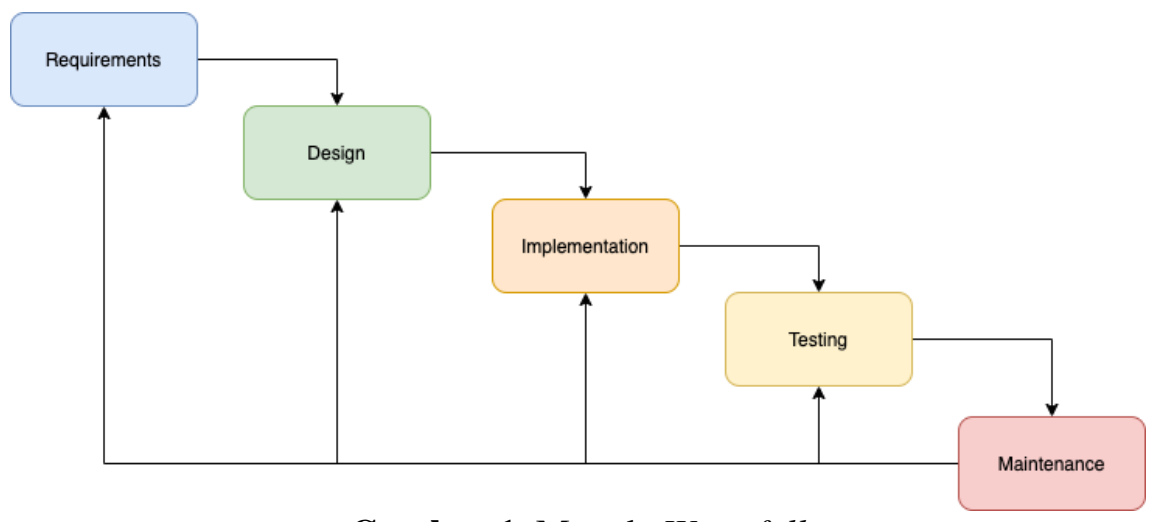

Gambar 1. Metode Waterfall

\subsection{Tahap Requirements}

Tahapan pembuatan website yang dilakukan adalah proses pengumpulan data dengan cara melakukan wawancara kepada bagian LPPM (Lembaga Penelitian \& Pengabdian Masyarakat) STIKI Malang dan observasi secara langsung proses yang sedang berjalan saat ini, sehingga didapatkan beberapa kebutuhan website diantaranya:

- Menampilkan daftar karya inovatif yang sudah mendapatkan Hak Cipta / Paten

- Menampilkan daftar karya inovatif yang masih berupa prototype

- Menampilkan informasi statistik karya inovatif

\subsection{Tahap Design}

Tahap berikutnya adalah melakukan proses desain berupa use case diagram, activity diagram, halaman antarmuka admin, halaman antarmuka halaman depan dan halaman formulir pengisian data karya inovatif. 


\section{a) Use Case Diagram}

Penggunaan use case diagram digunakan untuk menggambarkan sistem dari sudut pandang pengguna yang nantikan akan menggunakan sistem tersebut.

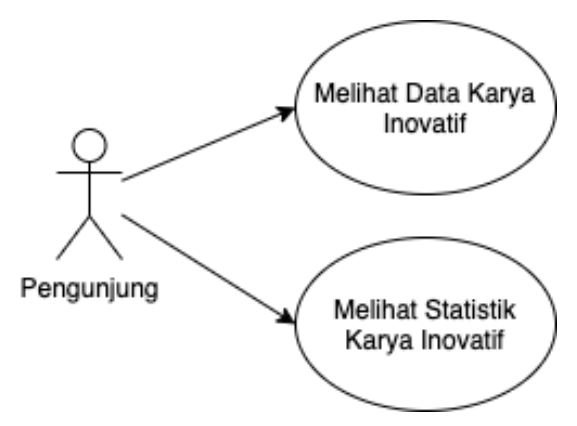

Gambar 2. Use Case Diagram Pengunjung Website

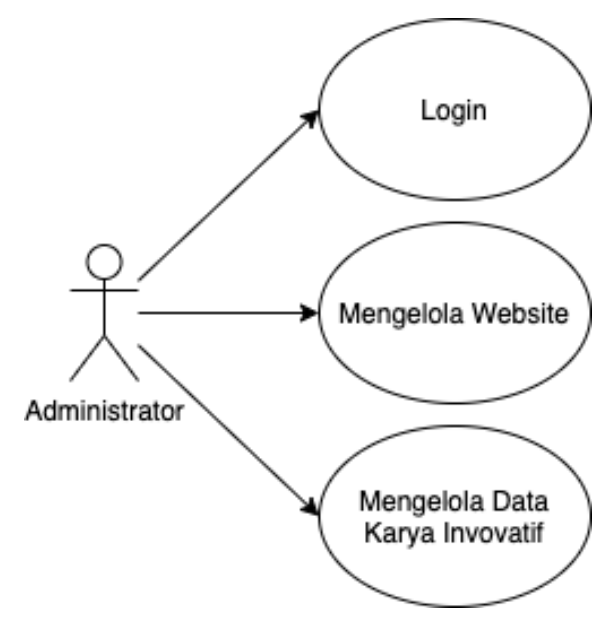

Gambar 3. Use Case Diagram User Administrator

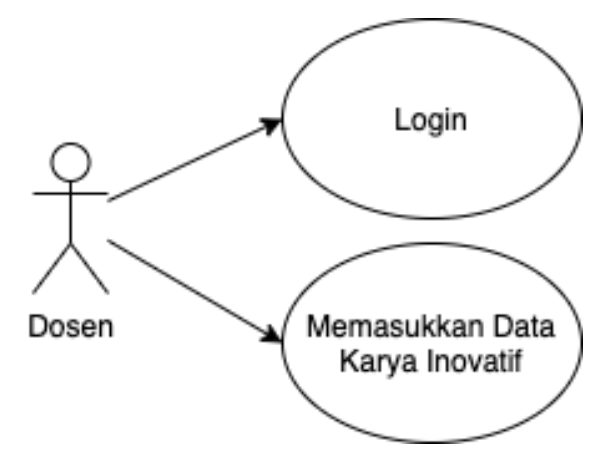

Gambar 4. Use Case Diagram User Dosen

User pengunjung adalah orang yang mengakses informasi data karya inovatif $\&$ melihat data statistik. User Administrator merupakan seseorang yang memiliki hak akses penuh tentang pengelolaan website mulai dari konten serta menambah atau menghapus User. Sedangkan User Dosen bertugas untuk memasukkan data karya inovatif ke sistem.

\section{b) Activity Diagram}

Diagram alur menunjukkan aktifitas proses yang terjadi di sistem informasi karya inovatif. Dimana pengunjung awalnya mengakses halaman depan kemudian sistem akan menampilkan data karya 
inovatif dan pengunjung bisa melihat data karya serta statistiknya. Dosen bertindak sebagai user yang bertugas memasukkan data karya ke sistem, sedangkan tugas administrator akan melakukan validasi data yang telah dimasukkan oleh dosen.

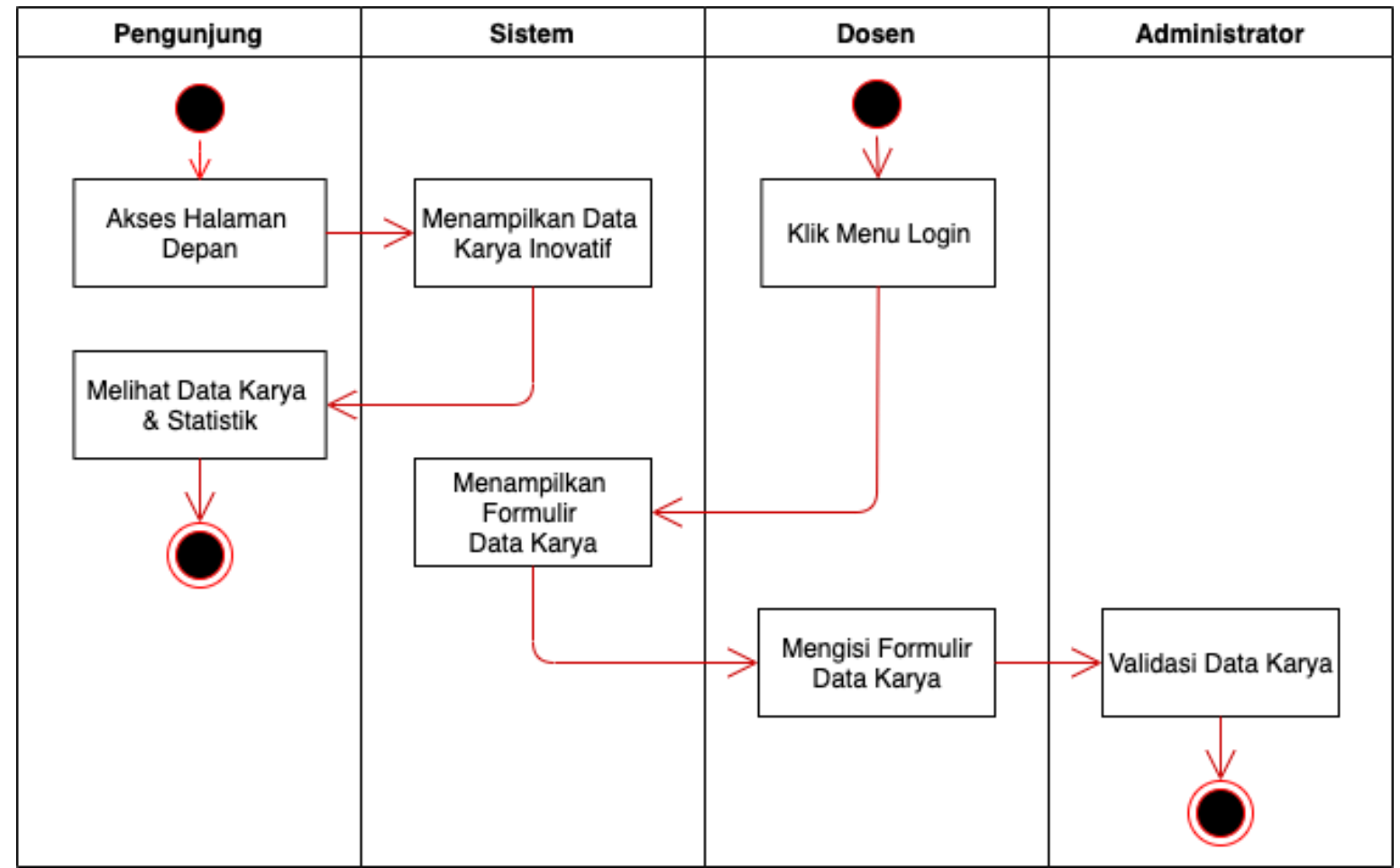

Gambar 5. Diagram Aktifitas Sistem Informasi Karya Inovatif

\section{c) Rancangan Tampilan Halaman Depan}

Merupakan tampilan utama dari sistem informasi karya inovatif yang bisa diakses oleh pengunjung. Terdiri dari beberapa bagian penting yaitu menu, pencarian, daftar karya dan statistik karya.

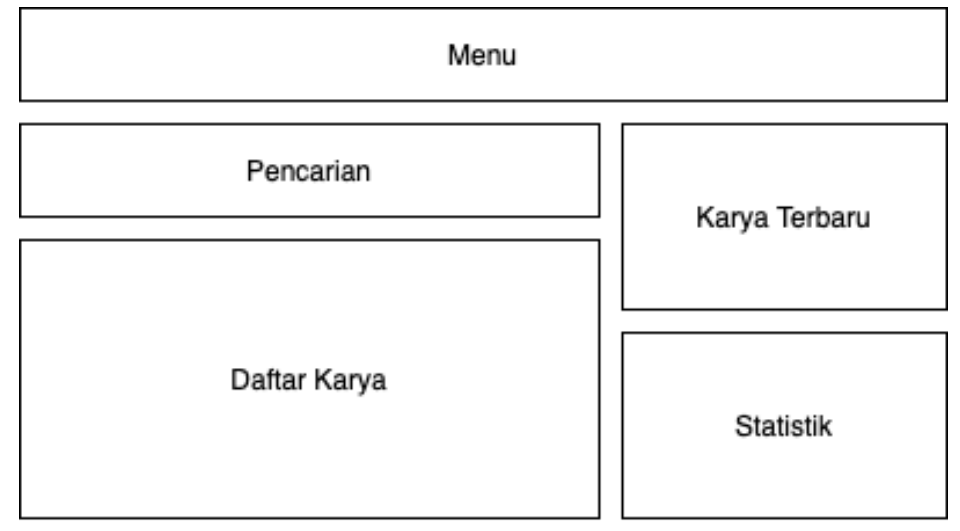

Gambar 6. Rancangan Halaman Depan

\section{d) Rancangan Tampilan Dashboard}

Dashboard adalah tampilan antarmuka antara sistem dengan user Administrator dan user Dosen. 


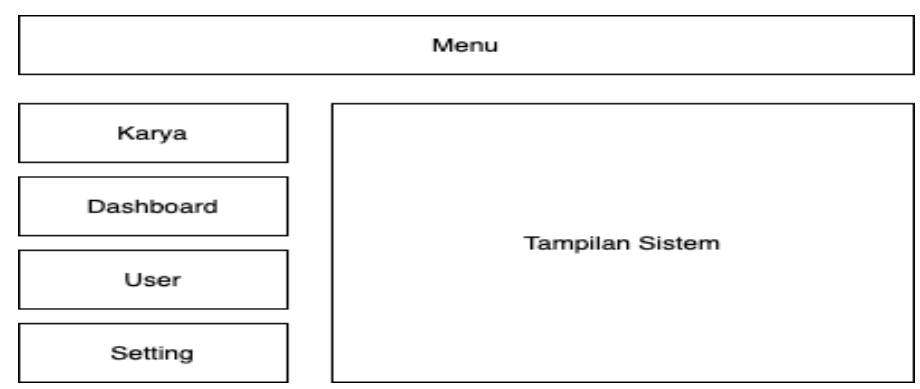

Gambar 7. Rancangan Tampilan Dashboard

\section{e) Rancangan Formulir Data Karya Inovatif}

Formulir data karya inovatif adalah tampilan antarmuka bagi dosen ketika akan memasukkan data karya ke sistem.

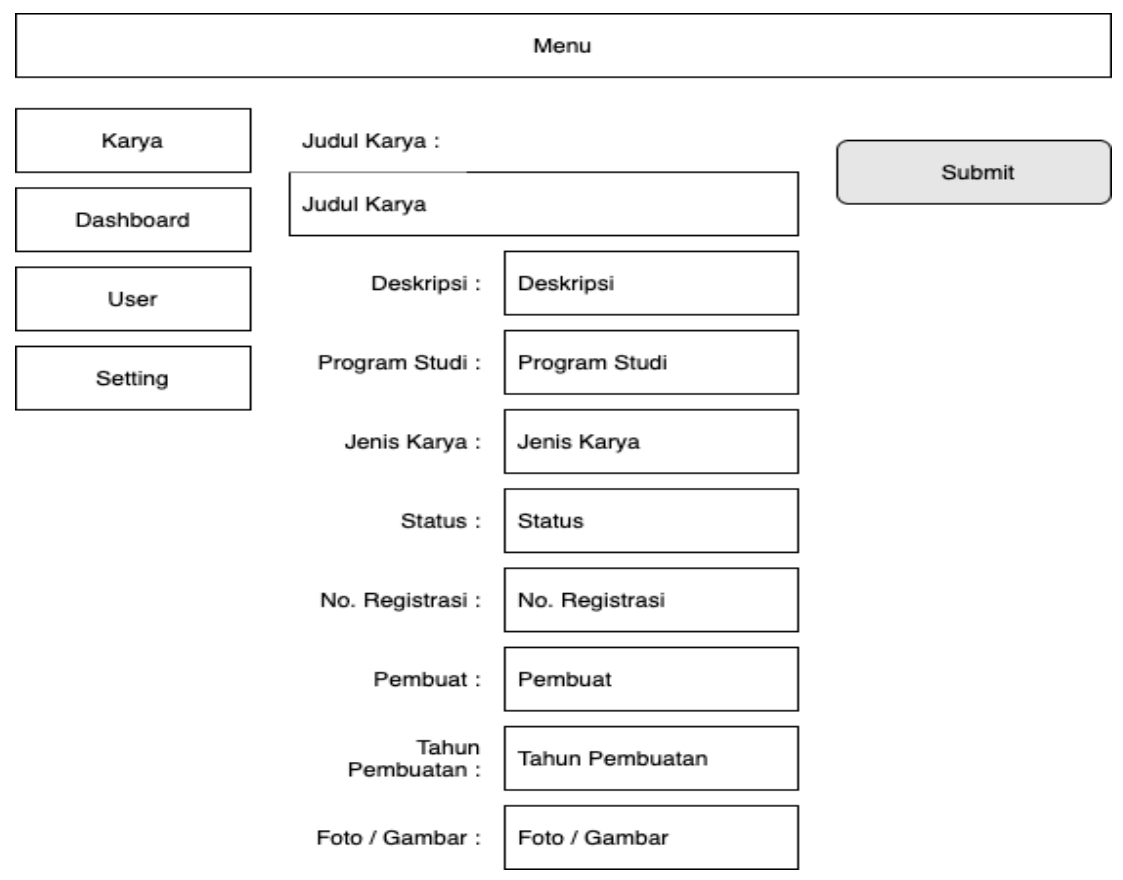

Gambar 8. Rancangan Formulir Data Karya Inovatif

\subsection{Implementation}

Tahapan implementation merupakan tahapan yang dilakukan untuk mewujudkan rancangan yang sudah dilakukan pada tahap sebelumnya. Beberapa tools penunjang dibutuhkan pada tahap implementation ini, diantaranya :

- XAMPP : digunakan untuk membuat web server

- Web Browser : digunakan untuk mengakses sistem

- Wordpress : digunakan untuk membuat sistem

- Advance Custom Fields : digunakan untuk menambahkan field pada antarmuka

- Pods - Custom Content Types and Fields : digunakan untuk menambahkan content types

\section{a) Pembuatan Halaman Depan}




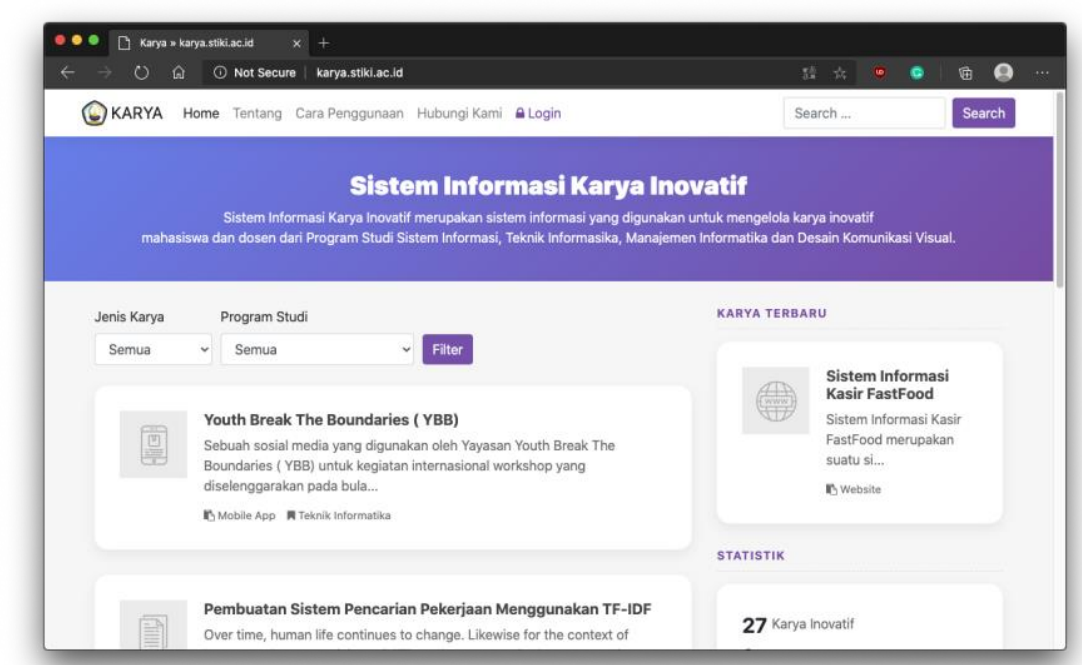

Gambar 9. Antarmuka Halaman Depan

b) Pembuatan Halaman Dashboard

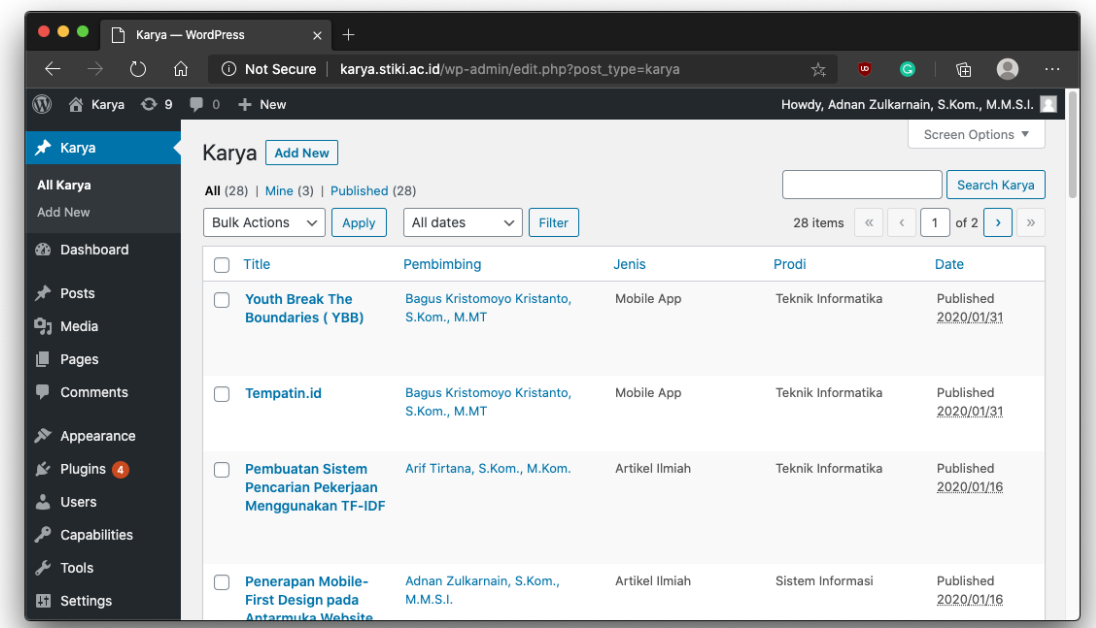

Gambar 10. Antarmuka Halaman Dashboard

c) Pembuatan halaman formulir data karya inovatif 


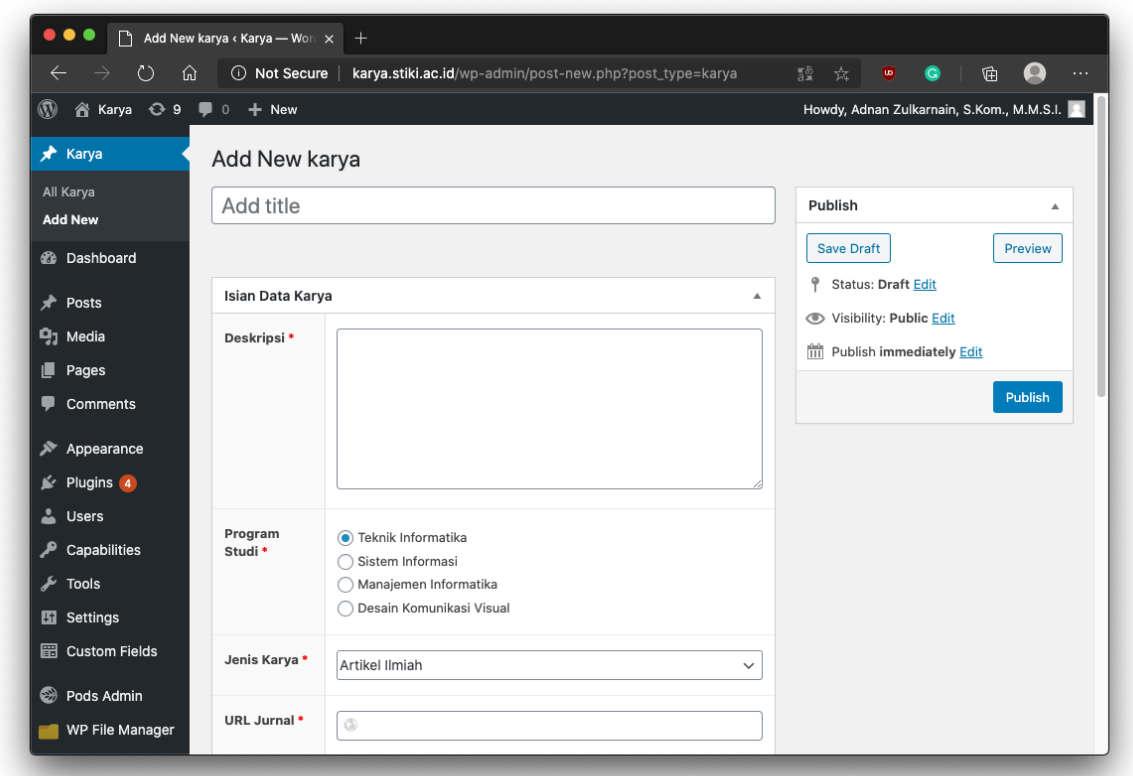

Gambar 11. Antarmuka Halaman Formulir Data Karya Inovatif

\subsection{Pengujian}

Tahapan pengujian pada sistem dilakukan menggunakan metode black box karena metode black box adalah metode pengujian yang berfokus menguji fungsionalitas dari sebuah sistem (Putra, Andriyanto, Karisman, \& Harti, 2020; Tirtana, Zulkarnain, \& Listio, 2019).

Pengujian dilakukan pada sistem informasi karya mahasiswa terdiri dari tiga pengujian, yaitu : pengujian pada halaman depan, halaman dashboard, dan halaman formulir data karya.

\section{HASIL \& PEMBAHASAN}

Hasil dari pengujian yang dilakukan menggunakan metode black box testing adalah :

Tabel 1. Hasil Pengujian Halaman Depan

\begin{tabular}{|c|l|l|}
\hline No. & Pengujian & Status \\
\hline 1 & Fitur Menu & Baik \\
\hline 2 & Fitur Pencarian & Baik \\
\hline 3 & Fitur Display Daftar Karya & Baik \\
\hline 4 & Fitur Display Statistik & Baik \\
\hline 5 & Fitur Login & Baik \\
\hline
\end{tabular}

Tabel 2. Hasil Pengujian Halaman Dashboard

\begin{tabular}{|c|l|l|}
\hline No. & Pengujian & Status \\
\hline 1 & Fitur Menu Karya & Baik \\
\hline 2 & Fitur Menu Dashboard & Baik \\
\hline 3 & Fitur Menu User & Baik \\
\hline
\end{tabular}


Tabel 3. Hasil Pengujian Halaman Formulir Data Karya Inovatif

\begin{tabular}{|c|l|l|}
\hline No. & Pengujian & Status \\
\hline 1 & Fitur Menambahkan Data & Baik \\
\hline 2 & Fitur Menampilkan Data & Baik \\
\hline 3 & Fitur Mengedit Data & Baik \\
\hline 4 & Fitur Menghapus Data & Baik \\
\hline
\end{tabular}

Hasil dari pengujian menggunakan metode black box diatas menunjukkan hasil yang baik sehingga secara fungsionalitas sistem ini siap untuk digunakan.

\section{KESIMPULAN \& SARAN}

Pembuatan sistem informasi menggunakan CMS (Content Management System) Wordpress dapat dengan mudah dilakukan karena CMS wordpress sangat mudah untuk di kustomisasi sesuai dengan kebutuhan serta telah dilakukan pengujian menggunakan metode black box didapatkan hasil fitur-fitur yang ada pada sistem informasi karya inovatif dapat berjalan dengan baik.

Saran untuk pengembangan penelitian selanjutnya adalah bagaimana menggunakan CMS (Content Management System) Wordpress dapat digunakan untuk mengembangkan sistem informasi yang lebih kompleks.

\section{DAFTAR RUJUKAN}

Ardiastuti, Y., Widarno, B., \& Harimurti, F. (2020). ANALISIS FAKTOR YANG MEMPENGARUHI PELAPORAN KEUANGAN PERUSAHAAN MELALUI INTERNET. Jurnal Akuntansi Dan Sistem Teknologi Informasi, 15(4).

Handayani, I., Febriyanto, E., \& Kristanti, C. Y. (2019). Komunikasi Dalam Pembelajaran Ilearning Plus Di. 16(2).

Hidayat, T., \& Muttaqin, M. (2020). Pengujian sistem informasi pendaftaran dan pembayaran wisuda online menggunakan black box testing dengan metode equivalence partitioning dan boundary value analysis. Jutis (Jurnal Teknik Informatika), 6(1), 25-29.

Karim, A., \& Purba, E. (2019). Sistem Informasi Pengolahan Data Nilai Berbasis Web. Seminar Nasional Teknologi Komputer \& Sains (SAINTEKS), 1(1).

Purba, E., Karim, A., \& Trianovie, S. (2020). SISTEM INFORMASI PENDATAAN USAHA MICRO KECIL DAN MENENGAH PADA DINAS UMKM LABUHANBATU BERBASIS WEB. Jurnal Ilmiah INFOTEK, 4(3).

Purwati, A. A., Suryani, F., \& Hamzah, M. L. (2020). Pengaplikasian Sistem Informasi Pencatatan Keuangan pada Koperasi Serba Usaha Karya Mentulik. Community Engagement and Emergence Journal (CEEJ), 1(1), 22-26.

Putra, A. P., Andriyanto, F., Karisman, K., \& Harti, T. D. M. (2020). PENGUJIAN APLIKASI POINT OF SALE MENGGUNAKAN BLACKBOX TESTING. Jurnal Bina Komputer, 2(1), 74-78.

Rachmatsyah, A. D., Nafisha, N. L., \& Prasetyo, F. (2019). Penerapan Metode Waterfall dalam Rancang Bangun Aplikasi Penyewaan Alat Perkemahan pada Selamet Outdoor Tambun. Teknomatika, 9(1).

Rochman, A., Hanafri, M. I., \& Wandira, A. (2020). Implementasi Website Profil SMK Kartini Sebagai Media Promosi dan Informasi Berbasis Open Source. Academic Journal of Computer Science Research, 2(1).

Tirtana, A., Zulkarnain, A., \& Listio, Y. D. (2019). Pembuatan Sistem Pencarian Pekerjaan Menggunakan TF-IDF. Jurnal Ilmiah Teknologi Informasi Asia, 13(2), 91-100. 